\title{
Application of Artificial Intelligence and Wireless Networks to Music Teaching
}

\author{
Yue Guan (iD) and Fangfang Ren \\ College of Humanities, Jiangnan University, Wuxi, Jiangsu, China \\ Correspondence should be addressed to Yue Guan; guanyue0212@jiangnan.edu.cn
}

Received 8 October 2021; Accepted 10 November 2021; Published 13 December 2021

Academic Editor: Narasimhan Venkateswaran

Copyright ( $) 2021$ Yue Guan and Fangfang Ren. This is an open access article distributed under the Creative Commons Attribution License, which permits unrestricted use, distribution, and reproduction in any medium, provided the original work is properly cited.

\begin{abstract}
The study is aimed at improving student's learning ability and constructing an intelligent, all-around, and three-dimensional innovative classroom by using intelligent technology. Middle school $\mathrm{C}$ is taken as the research object. First, the current situation of music teaching in middle school $\mathrm{C}$ is analyzed, and an intelligent music teaching mode suitable for middle school $\mathrm{C}$ is designed. Second, the intelligent music teaching mode is applied in the actual teaching process, and students' feelings for intelligent music classrooms are explored by a questionnaire survey. Finally, the teaching effect is analyzed. The results show that $96.7 \%$ of the students hold a positive attitude towards the new teaching mode, indicating that contemporary students have relatively high adaptation to and recognition with the development of artificial intelligence (AI). 84\% of the students are not particularly skilled in the operation of the intelligent network platform, and $9.3 \%$ of the students believe that the operation of the platform is relatively difficult. Therefore, teachers should teach students how to use tablets. 95\% of the students hold that teachers can quickly find teaching resources related to the course content on the tablet and introduce them to students in the teaching process, indicating that teachers are familiar with the usage of new teaching equipment. On the whole, students have a good experience of the new teaching mode. This new teaching mode based on AI is a response to the new course concept proposed in China.
\end{abstract}

\section{Introduction}

Nowadays, the scientific and technological revolution is booming. Artificial intelligence (AI), as an important driving force of the current industrial revolution, is constantly changing people's living and production modes, making human society enter a new era of human-machine fusion, sharing, and intelligence $[1,2]$. AI, as the core of the current scientific and technological revolution, is applied to the field of education and teaching [3]. With the rapid development of AI, intelligent classrooms have been widely used in music teaching. Different from the traditional teaching mode, the intelligent classroom can enable students to find pleasure in the learning process and form the awareness of independent inquiry. In recent years, the development of wireless networks also provides a platform for intelligent classroom teaching. The use of high-tech products such as tablets, computers, and electronic schoolbags, helps to widen students' learning channels and arouse students' interest in learning [4-7].

The intelligent classroom is different from the traditional teaching mode. It integrates some new technologies with classroom teaching. Its goal is to provide students with a better learning environment, and then improve students' learning effect [8]. After relevant literature is reviewed, it is found that the research on the intelligent classroom in China starts late and the number of the relevant research is little. Some researchers believe that the "intelligent learning environment" means the use of all existing technical means and resources based on AI, big data, virtual reality (VR), cloud computing, and other technologies under the integration of "Internet + " the learning environment, forming a highly intelligent learning environment [9-12]. As a new teaching mode, the intelligent classroom can meet the teaching needs of teachers and create a good learning environment for students $[13,14]$. At present, the intelligent classroom plays an 


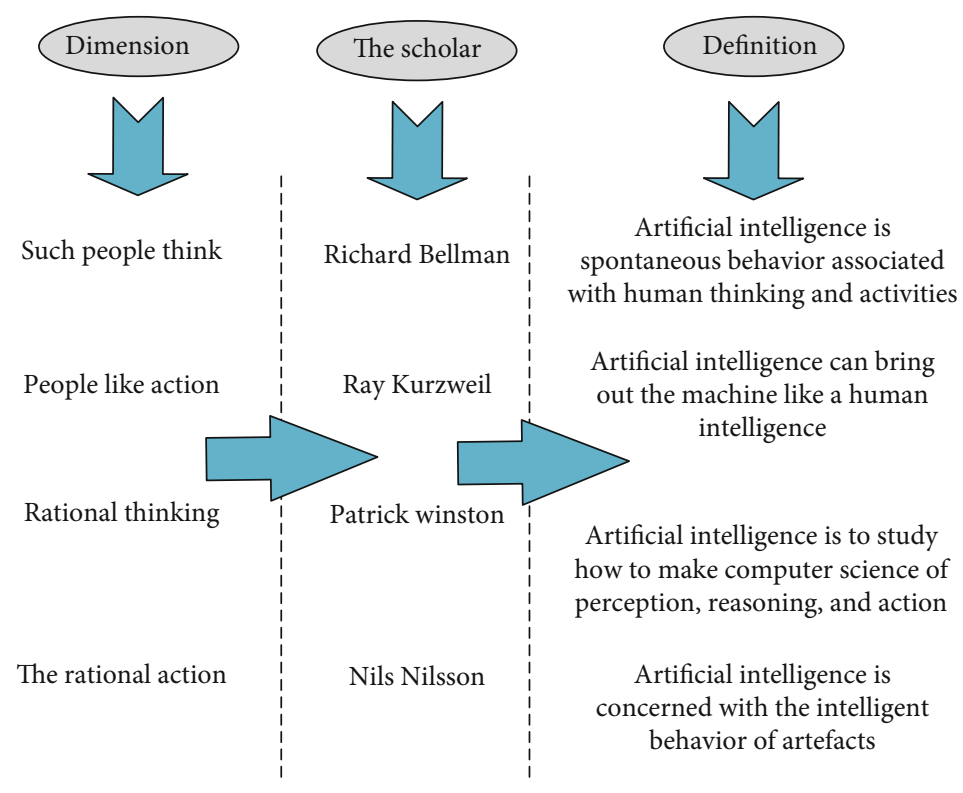

FIgURE 1: Definitions of AI in four dimensions.

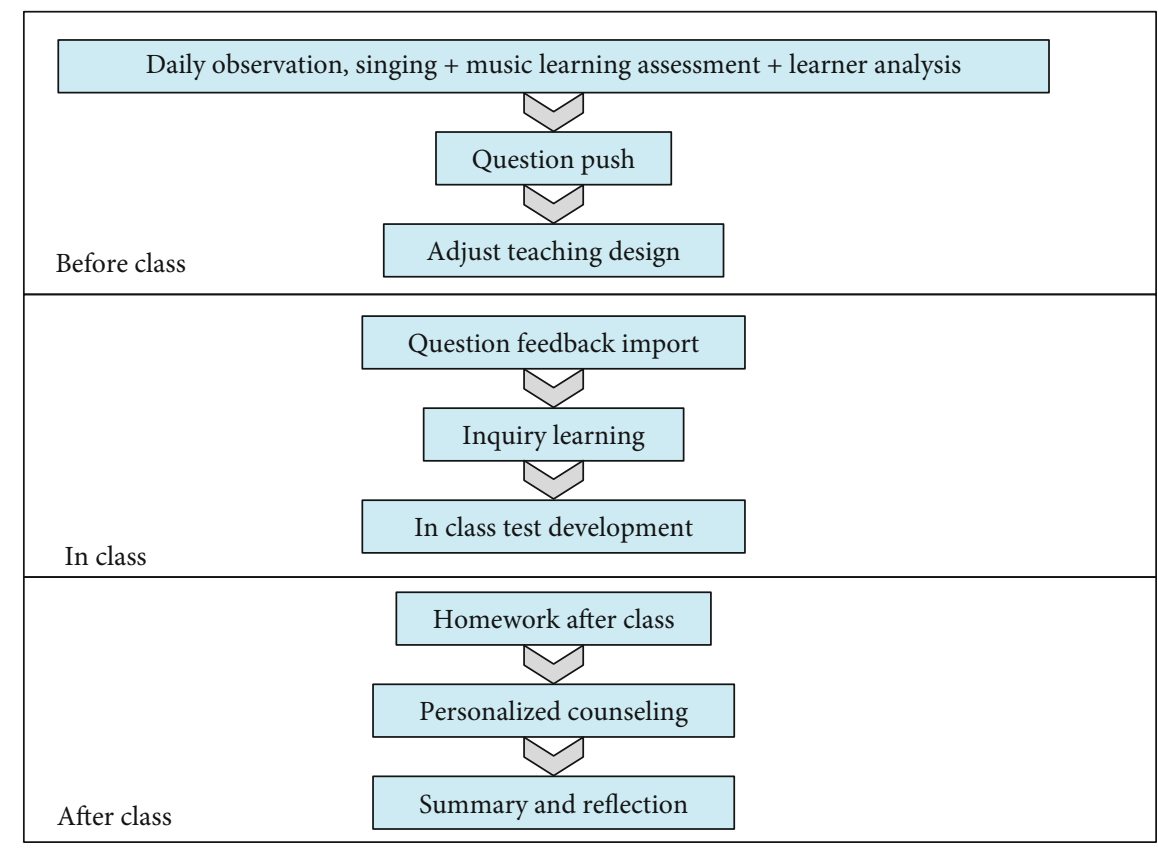

Figure 2: Design of an intelligent music class.

important role in modern teaching, which attracts the attention of many scholars in China.

Since the 21st century, there are more and more studies on the integration of the intelligent classroom and subject teaching, which lays a theoretical foundation for the study. However, it is found that there are few studies on the application of the intelligent classroom in China, and the research related to subject teaching is not mature after relevant literature is reviewed. There is no research on the integration of $\mathrm{AI}$ and music teaching. Therefore, an intelligent music class- room teaching mode suitable for middle school $\mathrm{C}$ is designed based on the theory of AI and applied to the teaching process. Then, the teaching effect is summarized and analyzed. The study meets the requirements of the new course concept and has strong practical significance.

\section{Materials and Methods}

The term "AI" appears in the mid-20th century at an academic conference at Dartmouth College. With its 


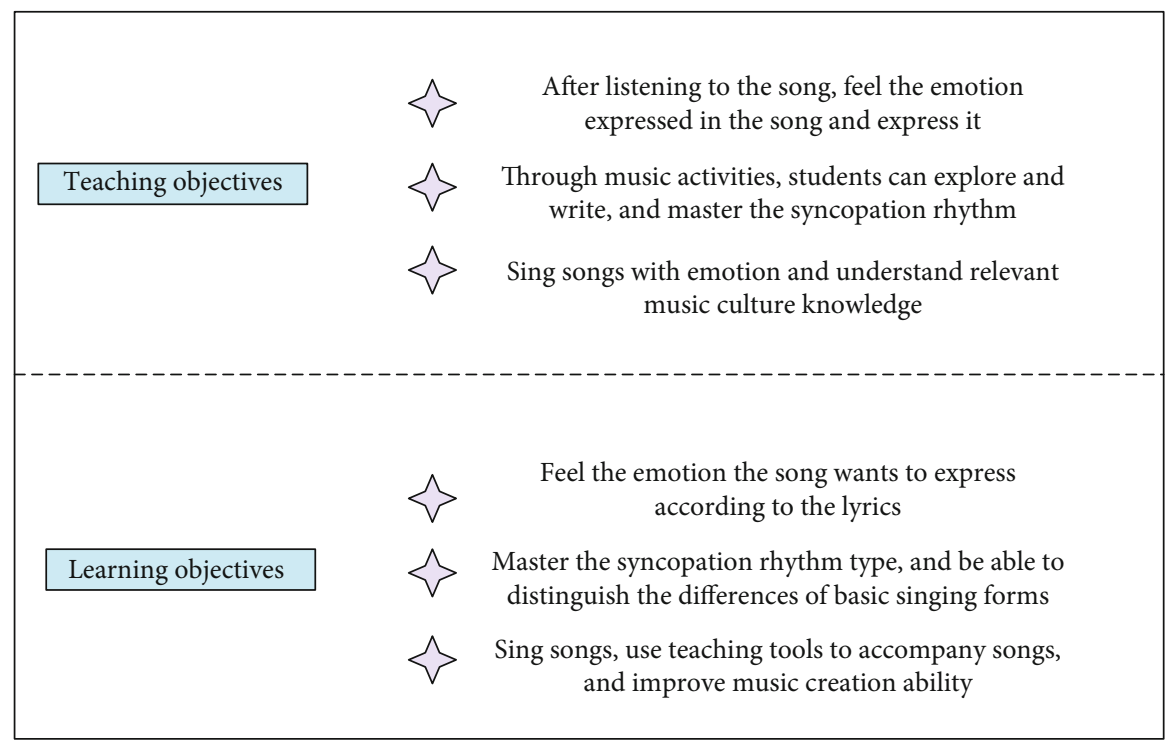

Figure 3: Teaching objectives.

development, AI is applied in many fields, and the effect is remarkable. Its research fields include image processing, pattern recognition and other computer vision fields, speech synthesis and recognition of language communication and understanding, the social common sense in the cognitive field, mechanical control, design and manufacture, the cooperation between robots and humans; and machine learning (ML). Thus, the application field of AI is very broad, covering almost all aspects of life $[15,16]$. However, the definition of artificial intelligence is not very definite at present. In its development process, researchers make different explanations from different aspects. Here, four representative definitions are listed, as shown in Figure 1.

Based on its definitions, AI can be understood as follows: it is a branch of computer science, and some people also call it machine intelligence; that is, it is opposite to natural intelligence and it is the intelligence presented by the machine [17]. The intelligence presented by machines is the imitation of natural intelligence. With the continuous development of science and technology, AI is constantly updated, and even has natural thinking, having the ability to replace human beings to complete some tasks that cannot be realized by human beings. Therefore, AI is different from the previous simple and fixed computer algorithms and programming although it belongs to computer science. It can analyze and summarize the collected data and then make rapid responses and operations to the environment.

\section{Music Class Survey and Case Study on Middle School C}

Middle school C is founded in 1998. It has two campuses of a middle school and a high school, and there are six music teachers. The school has a new intelligent system like intelligent classrooms and studios.

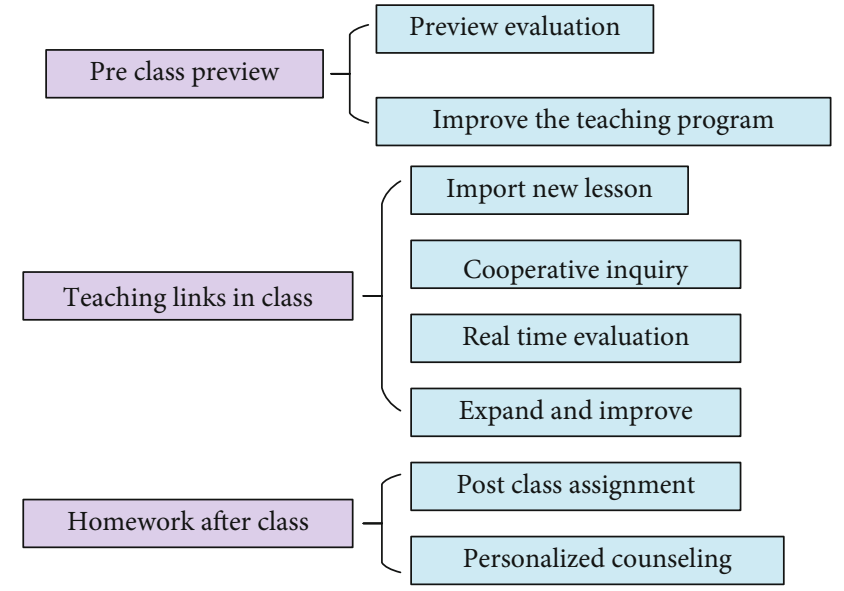

FIGURE 4: Teaching links.

(1) Current situation of music classroom teaching of middle school C

Through the field investigation, it is found that the music teaching of middle school $\mathrm{C}$ has the following problems: first, the 5teachers and students of the school pay much less attention to the music class than the main subjects like English, and the number of English teachers often take up the music class. This shows that the music class does not attract the attention of teachers and students in the school, and still maintains the traditional teaching concept, which may hinder the comprehensive development of the subject in the new era. Second, the teaching mode is single, and the teachers do not care about students' learning needs when preparing lessons. They do not have an in-depth understanding of the teaching objectives of music lessons, and just simply complete the teaching task through a single teaching mode, which lacks interaction with students in the 


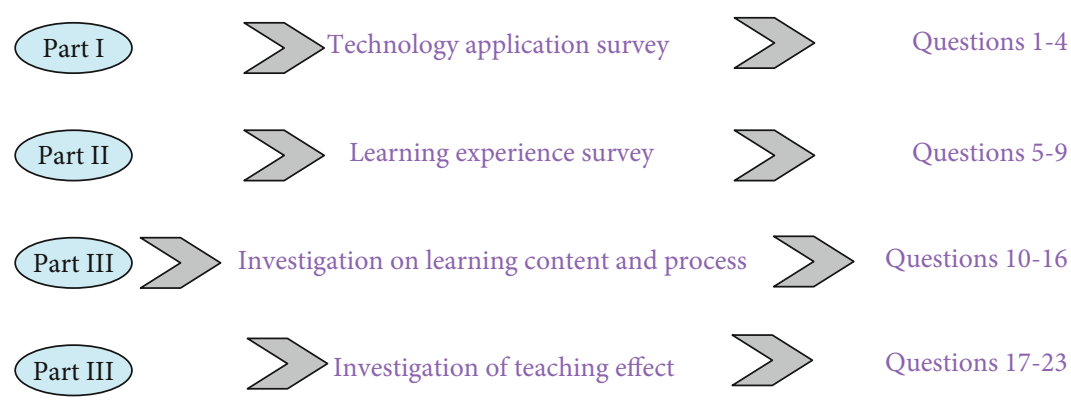

FIGURE 5: Design of the questionnaire.

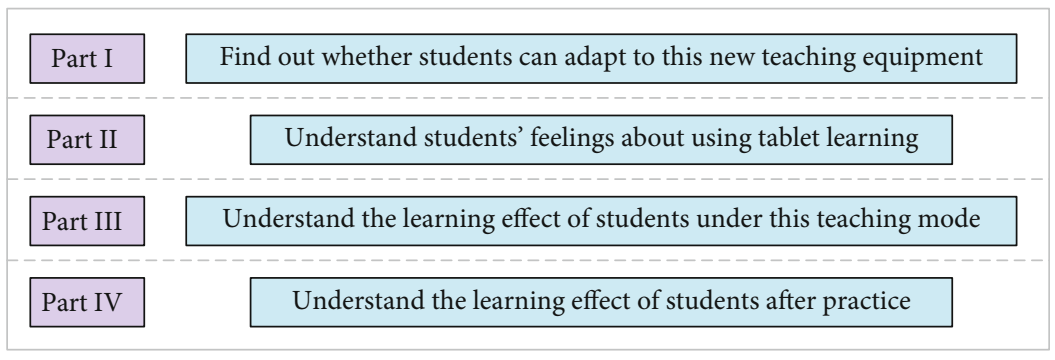

FIgURE 6: Meaning of each part of the questionnaire.

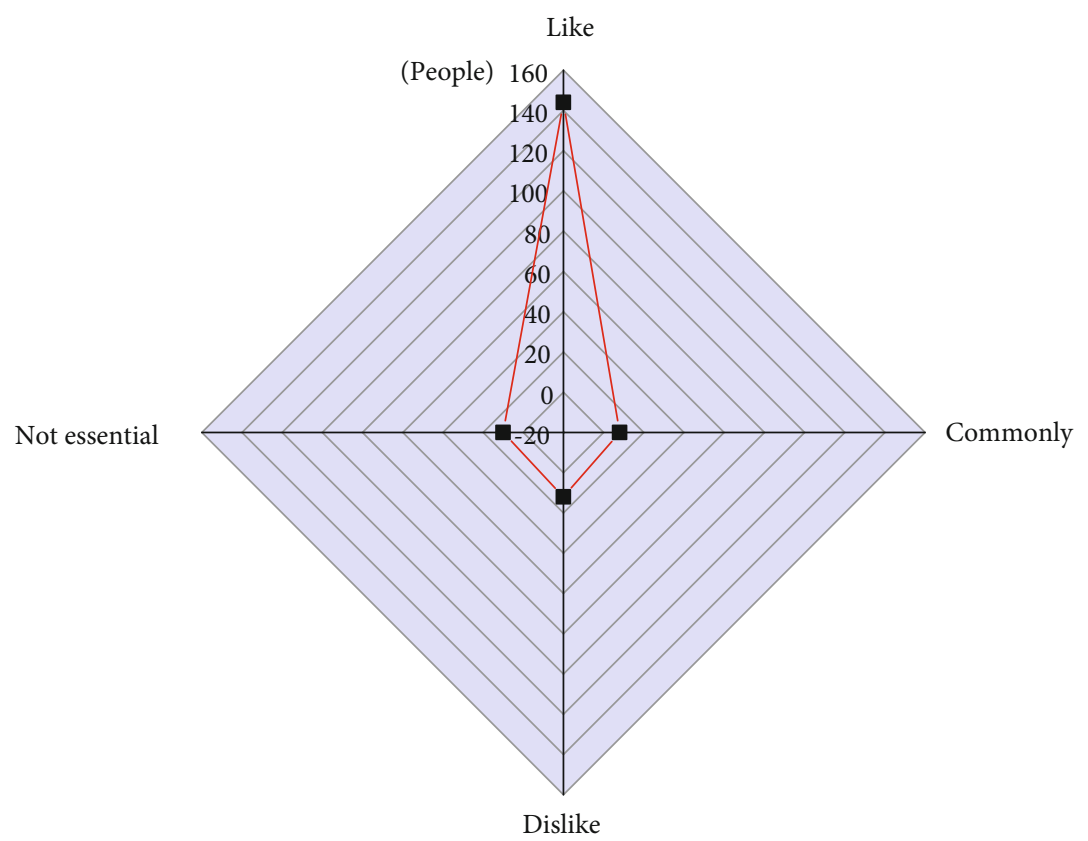

FIGURE 7: Students' feelings for the intelligent music class.

classroom, making students lose interest in the study. Third, the music class is often replaced by an English class or other classes, indicating that the music class is not paid enough attention by students and teachers, as well as schools [18].

(2) Design of the intelligent music classroom

Through the above analysis, the problems existing in the music classroom under the traditional teaching mode are explored. The intelligent music classroom is designed to tackle the problems, as shown in Figure 2:

Figure 2 shows the three teaching links, namely, before class, in class, and after class, in an intelligent music class. Before the class, teachers and students need to download the app of a school cloud platform on their tablets, and teachers need to find the electronic version of the music textbook in the library of the intelligent system and download it in advance. In the resource center of the system, the 


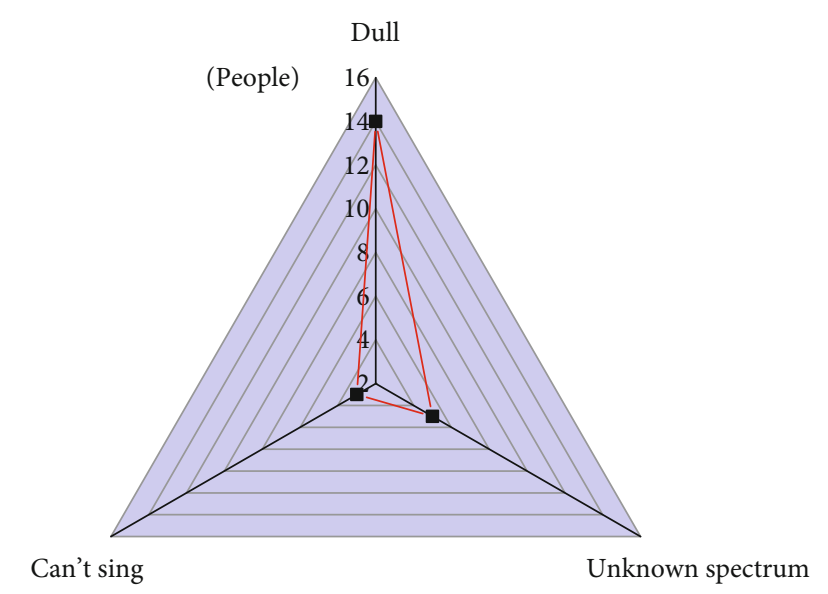

FIGURE 8: Reasons why students do not like the intelligent music class.

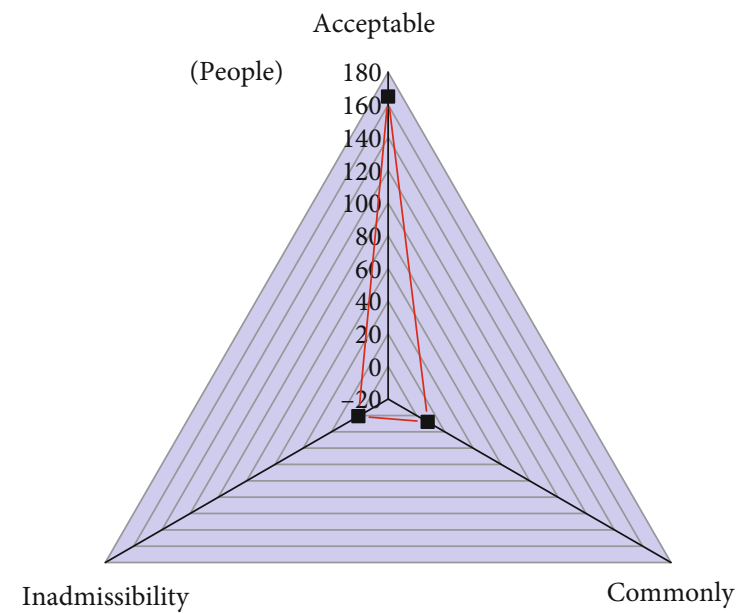

FIGURE 9: Survey results of students' acceptance degrees of using tablets.

materials needed for class are sorted out and placed in the lesson preparation plate for classroom use. And according to students' cognition, the needs of students are taken into account in the formulation of teaching programs $[19,20]$. In addition, teachers can organize some interesting preclass activities according to the teaching content, such as listening to songs and recognizing them and listening to a song, and following it. The system can present the preclass activities set by teachers to students, and the students perform them after the completion of the system. And then, teachers can make corresponding adjustments to the teaching content according to the evaluation of the system.

In the class, teachers can use the reading point of the intelligent system to play the piece of music they need to learn and sing. The story related to the song can be intuitively demonstrated through Flash animation to enhance students' emotions when they singing the song [21, 22]. Teachers can play the piano to accompany students when students sing songs and encourage students to innovate freely according to the accompaniments, which is conducive to improving the intimacy between teachers and students. The answer mode can be set as "race to be the first to answer a question" in the question link to arouse students' interest in music classes [23]. At the end of the class, teachers need to assign homework to students according to what they have learned to review the content of this lesson.

\section{(3) Teaching content and objectives}

The teaching content is the song "Clouds chasing the moon" published by the People's Music Publishing House for the students in the eighth grade. This song is a chorus suitable for collective learning and adapted according to its national orchestral version.

When the teaching objectives of the music class are designed, it is necessary to take into account not only the characteristics of students but also the characteristics of the teaching content in this section. The teaching objectives and learning objectives preset in the experiment are shown in Figure 3.

\section{(4) Implementation of the teaching process}

Intelligent teaching software, also known as a light intelligent classroom, under the banner of One School Science and Technology News, can analyze and summarize the students' learning process. And the intelligent music class is carried out by taking the song "Clouds chasing the moon" as the teaching content. The specific teaching links are shown in Figure 4.

In the preclass stage, teachers need to preset the goals to be achieved in this class according to students' cognitive ability and send the preclass questions to students. Teachers can check the completion of students' preclass tests in real time through platform data and supervise them timely. Students can turn to teachers for help through the system when they have difficulties in answering the questions in the test [24-26].

In the teaching process, students first need to $\log$ in on the system and join the intelligent class. Teachers can preview or introduce the content of the class, and show students the main content through PPT. And then they can teach students to follow the songs by using the sentence teaching in the system and record the learning process of students in time by using the brush-pen and focus, and the targeted teaching or interpretation should be given in response to their problems and difficulties $[27,28]$. Teachers should encourage students to use teaching aids for accompanying the song. In this way, students can feel the different artistic conceptions brought by different singing forms based on the group chorus. After the melodies of songs are acquired and the feelings to be expressed by songs are experienced, teachers need to further popularize the music theory of national orchestral music to students and enrich their music knowledge [29].

At the end of the class, teachers can send the afterschool exercises related to the teaching content to students based on the intelligent classroom system and require students to complete and submit within the specified time. After that, students can check their answers according to the correct answers issued by teachers. The teacher 


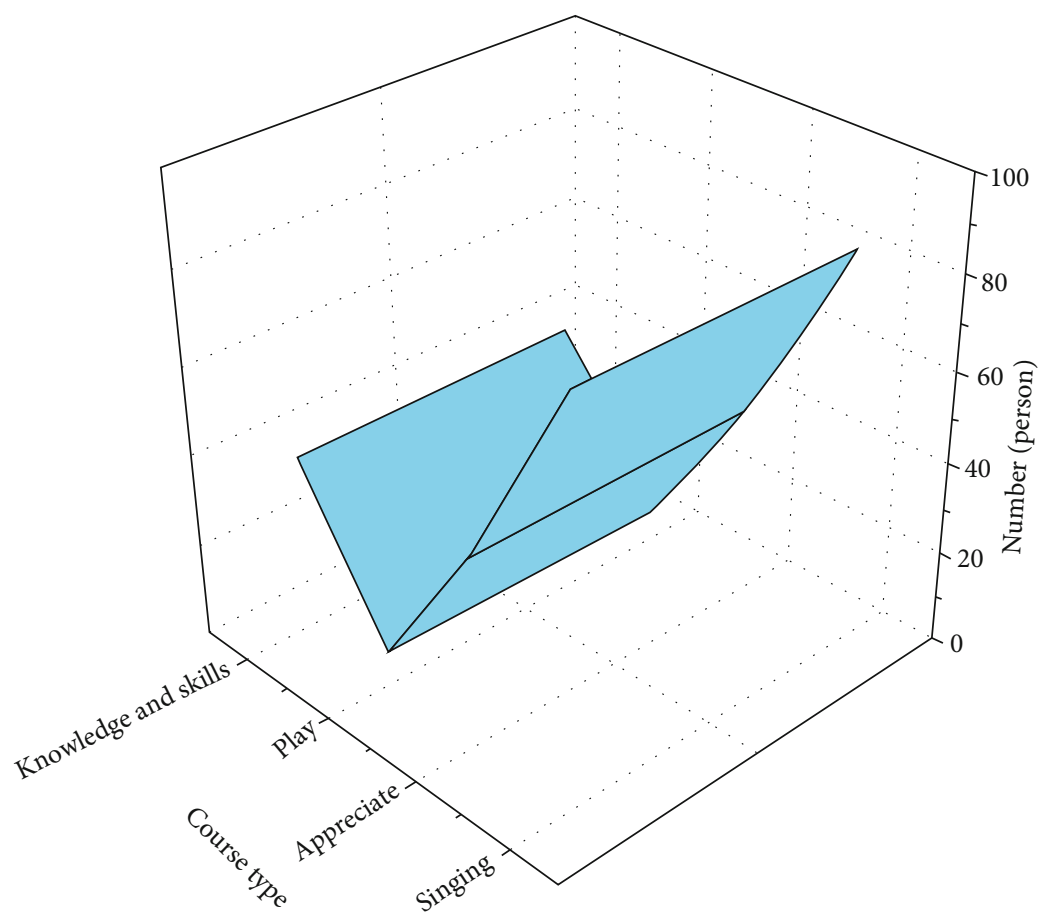

FIgURE 10: The teaching content of music classes for the students in grade 8 .

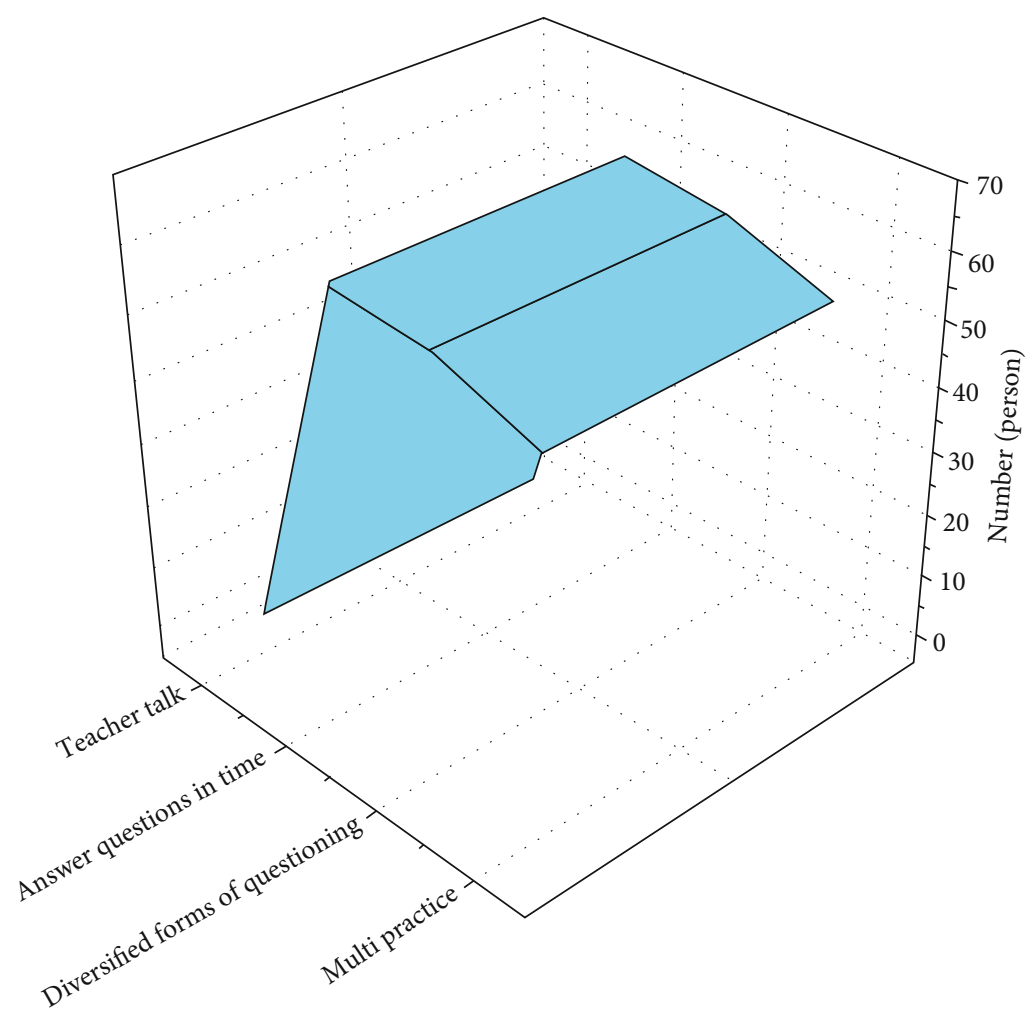

FIGURE 11: Interaction of students' expectations in the intelligent music classroom.

summarizes the students' problems in mastering the knowledge through the test and focuses on the explanation of the difficulties in the next class to improve students' learning efficiency.

\section{Research Design}

174 students from four classes in grade eight of middle school $\mathrm{C}$ are taken as the research subject to conduct a 


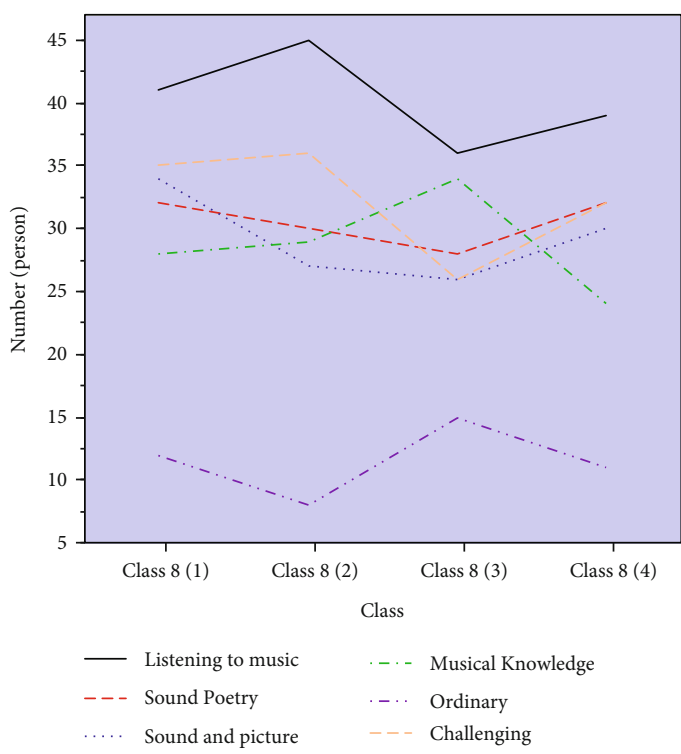

(a)

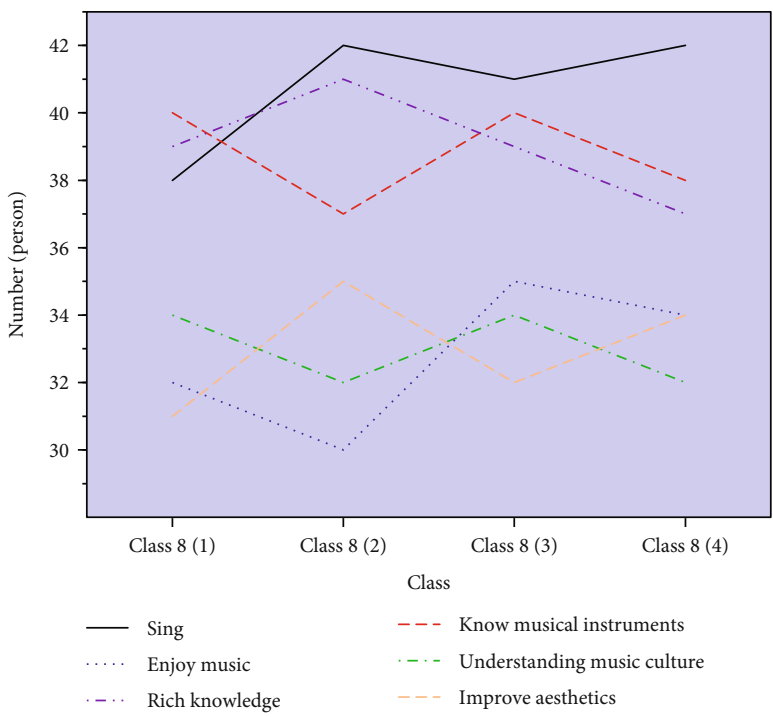

(b)

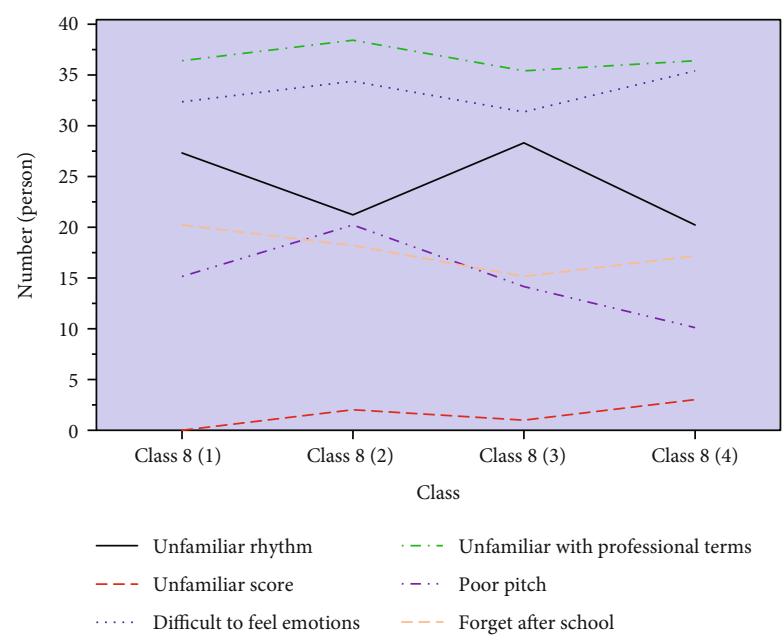

(c)

FIGURE 12: Survey results of multiple-choice questions: (a) the results of the preclass test; (b) the knowledge that students have learned in the classroom; (c) the difficulties encountered in the learning process.

questionnaire survey to analyze the teaching effect of the music intelligent class in middle school C [30]. Before the specific content of the questionnaire is designed, a large number of studies on the intelligent classroom of mathematics, sports, geography, and other subjects is reviewed, and a total of 23 questions are designed. The design and distribution of specific questions are shown in Figure 5.

Through the design of the above four parts, a deeper understanding of students' learning feelings and effects is obtained. The meaning of each problem designed is shown in Figure 6.

\section{Results}

5.1. Application Analysis of the Intelligent Music Classroom in Middle School C

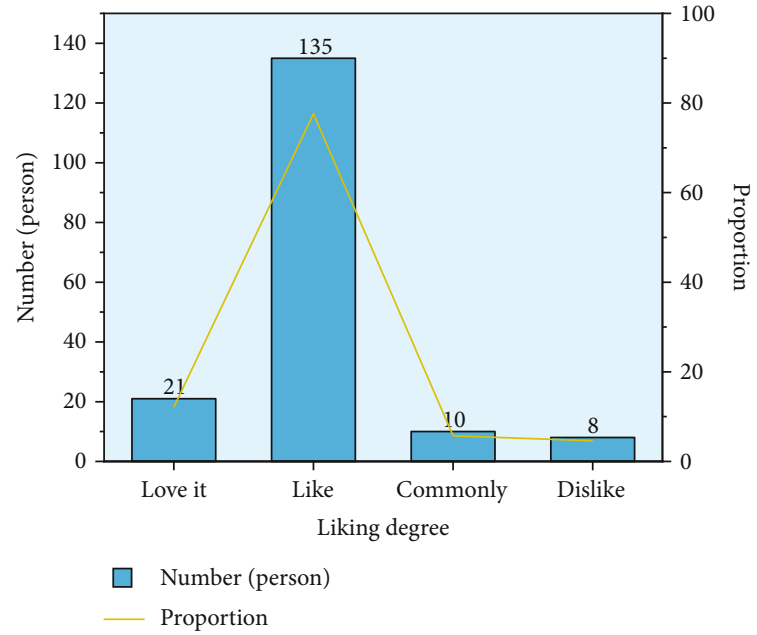

FIGURE 13: Students' feelings for the intelligent classroom. 


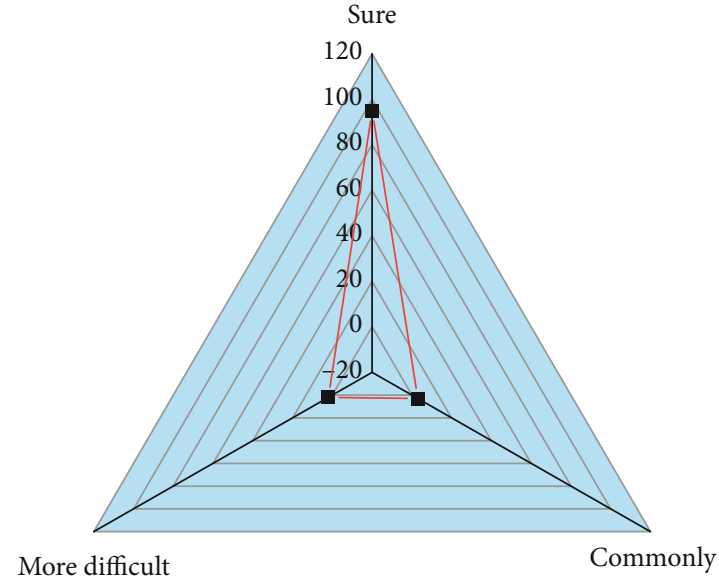

(a)

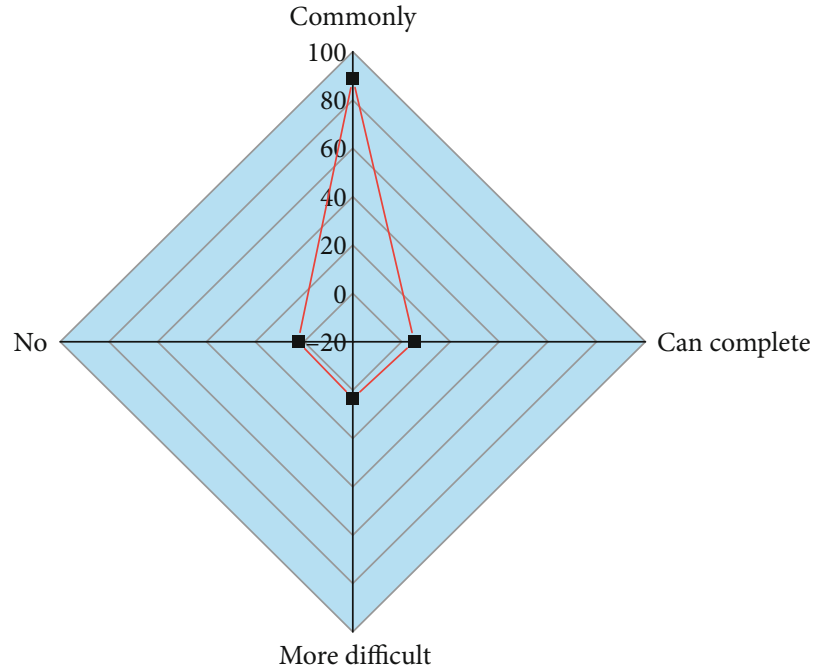

(b)

Figure 14: Operation of the intelligent classroom platform: (a) teachers quickly find the teaching resources on the platform; (b) knowing about how the platform works.

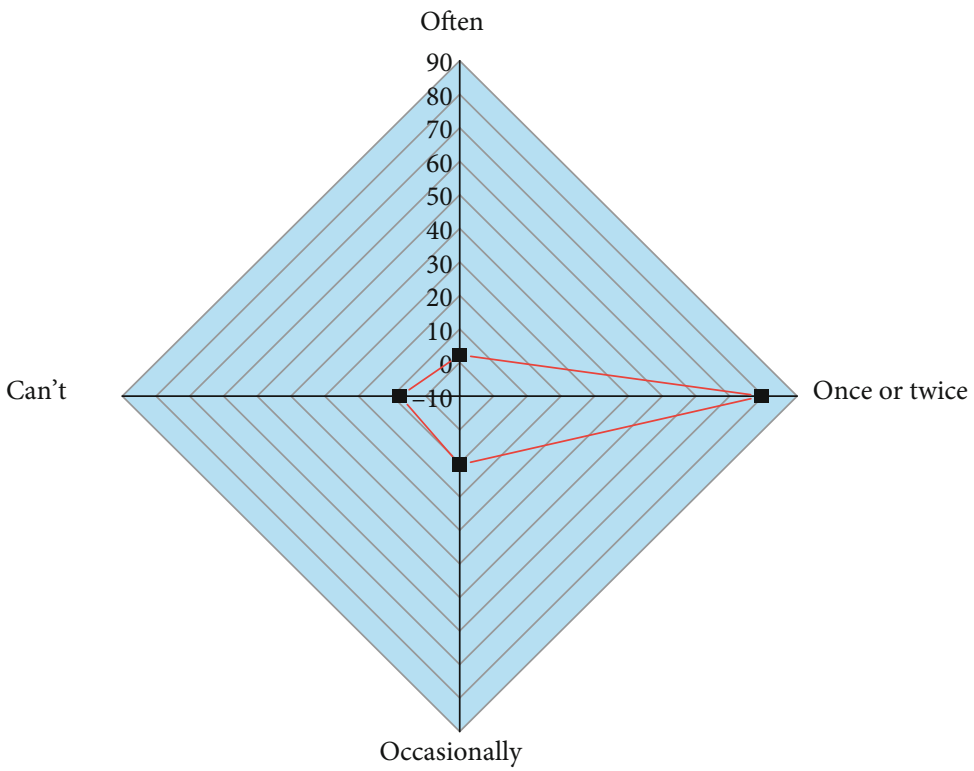

FIGURE 15: Survey of the network condition in the intelligent classroom teaching.

(1) Students' attitude to the intelligent music class

The students' feelings for the intelligent music class are divided into like, ordinary, dislike, and not essential. The survey results are shown in Figure 7.

Figure 7 shows that students are very interested in intelligent music classes. 144 students like the music classes, and only 10 students think that music lessons are not essential. However, students who do not like music lessons are more than those who do not like the music class.

And a further survey is conducted to reveal the reasons why students do not like the intelligent music class or think the class is not essential. The survey results are shown in Figure 8.

Figure 8 shows that the reason why most students do not like the intelligent music classes or think that music lessons are not essential is that music classes are too boring. Five of the students who do not like music lessons is that they do not know music scores and three of them feel that they cannot sing. This shows that the current music classroom teaching is not attractive and interesting and does not create a relaxed and pleasant learning atmosphere for students, resulting in students' negative attitudes to the traditional music classes.

(2) Survey results of students' proficiency in the use of tablets

The students' acceptance degrees of using tablets are divided into three levels: acceptable, neural, and unacceptable. The survey results are shown in Figure 9. 


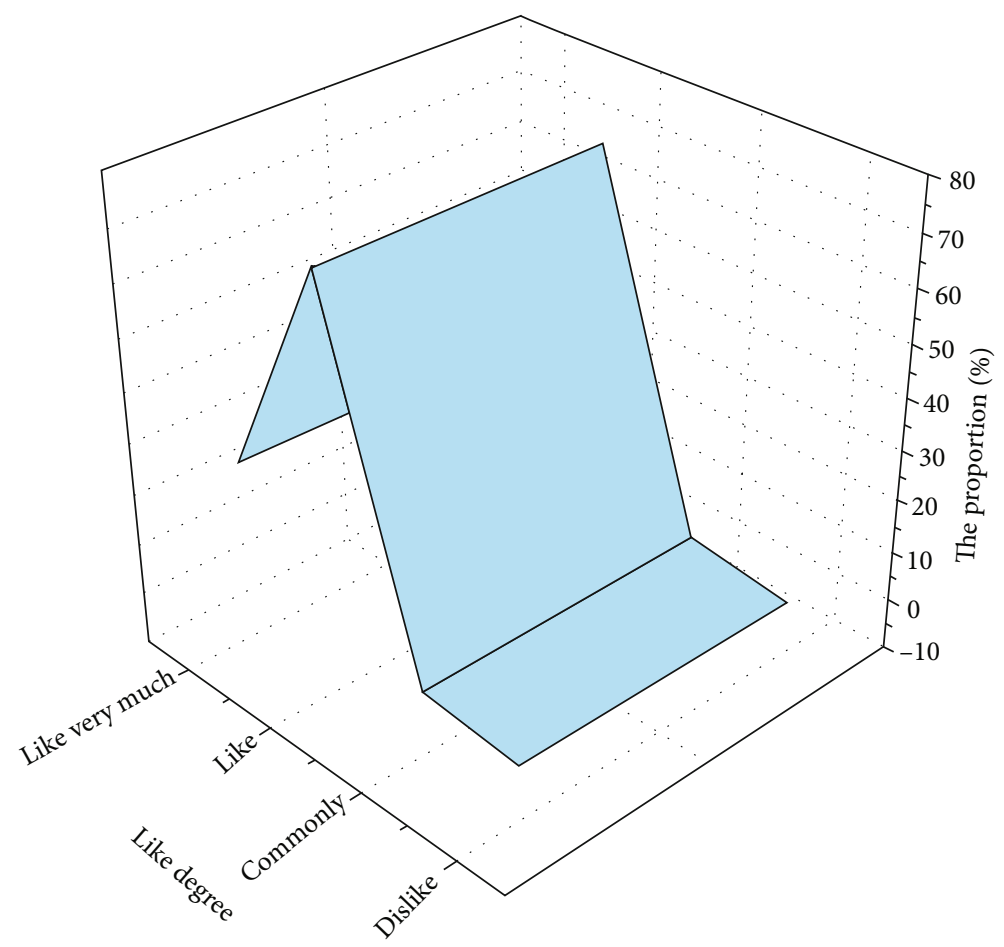

(a)

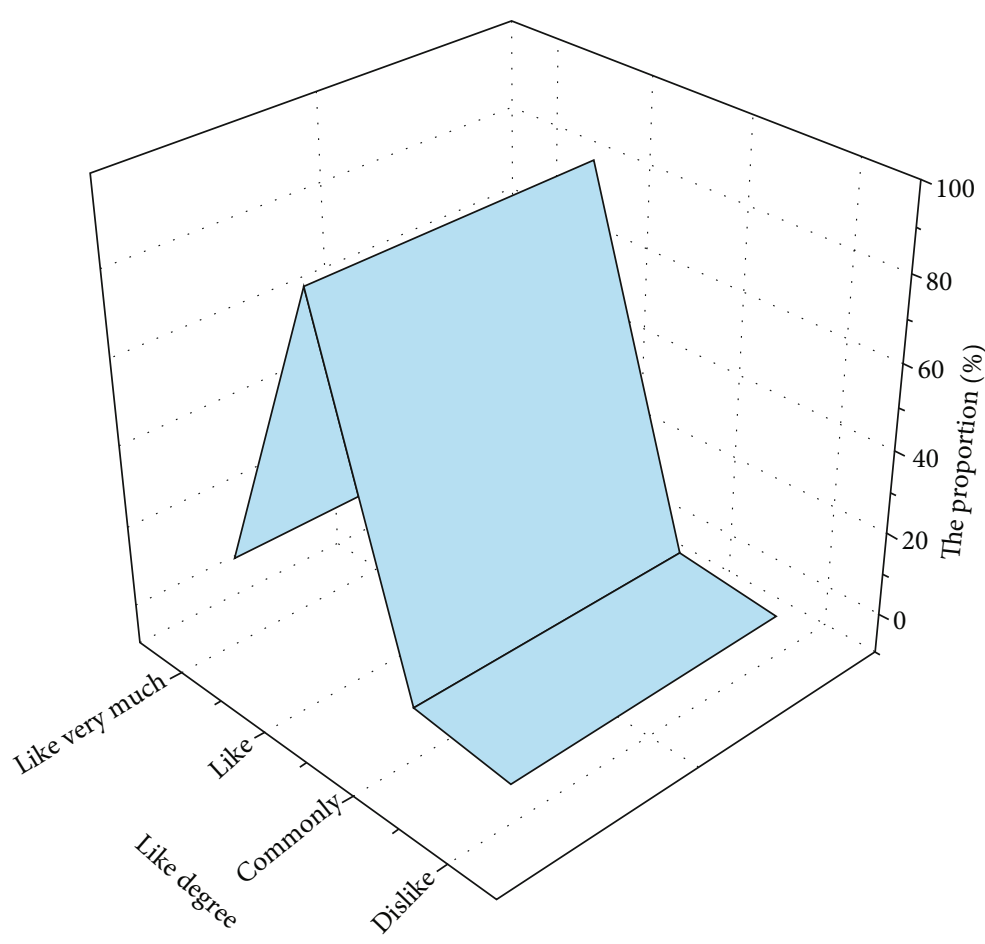

(b)

FIGURE 16: Students' experience of the intelligent classroom: (a) complete the homework based on the intelligent system; (b) the learning function provided by the intelligent system.

Figure 9 shows that 165 students can accept the learning mode of using tablets; 8 students are neural in using tablets in the classroom teaching; only one student cannot accept the use of tablets in the learning process. This shows that most students can accept intelligent music classroom teaching. This method is innovative and can attract students' attention to the knowledge of the music classes.

(3) Survey results of students' needs in the music classes 


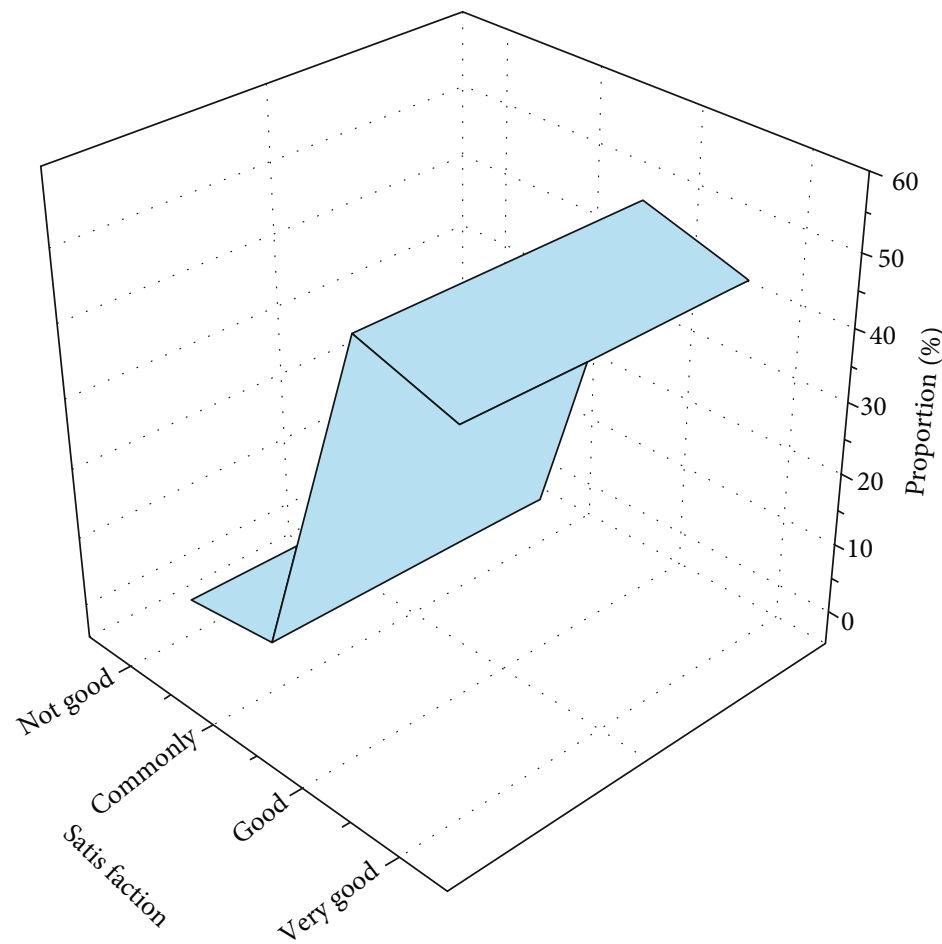

(a)

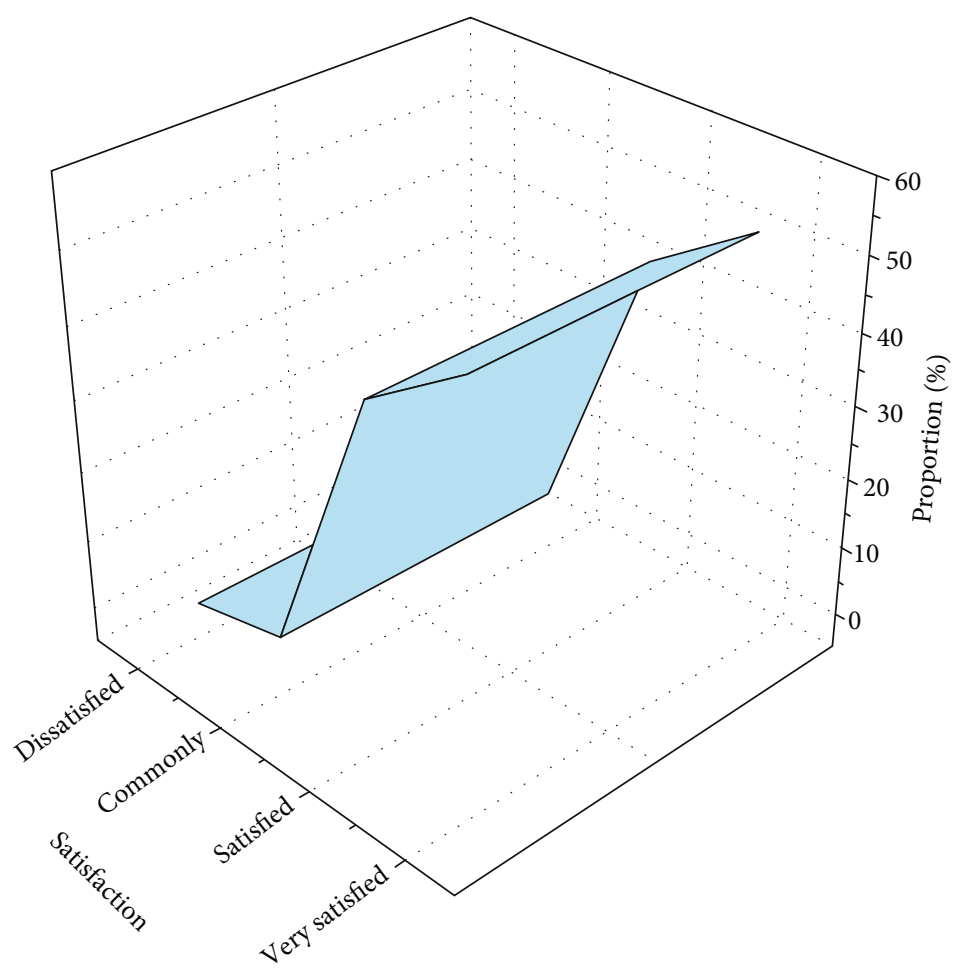

(b)

Figure 17: Survey of the satisfaction with the function and questioning form of the free speech platform: (a) the function of the free speech platform; (b) the questioning form of the free speech platform. 


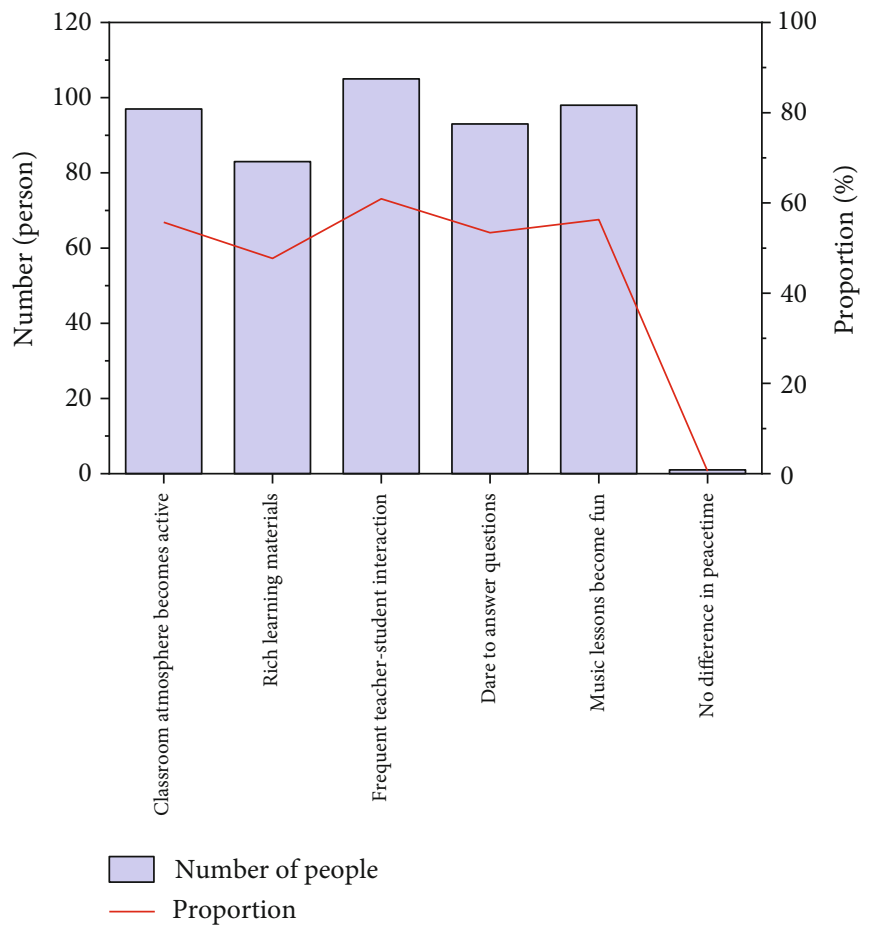

FIGURE 18: Students' feelings of using tablets for learning.

The teaching content of music classes for the students in grade 8 consists of four types: singing, appreciation, performance, and knowledge and skills. The results are shown in Figure 10.

Figure 10 shows that students' favourite content of the music class is singing and appreciation and students who like knowledge and skills are more than the former, indicating that students want to know more knowledge related to music in the music teaching classroom. Therefore, teachers need to integrate knowledge related to teaching content in music teaching.

In terms of the interaction in the music class, students' expectations are shown in Figure 11.

From Figure 11, it is found that most students think that there is a need for multipoint interaction between teachers and students in the music classroom, and a variety of ways are used to ask questions and to answer questions timely. On this basis, more practice is performed in the classroom. Only one student hopes to use the way of direct teaching in the intelligent music classroom.

This survey also involves some multichoice questions, and the survey results are shown in Figure 12.

Figure 12 shows that the students in the four classes all hope to hear more about songs in the preclass stage. They do not want the preclass test to be too simple and hope to challenge more complicated tasks. The students in the four classes all believe that the music classroom should be aimed at singing, being familiar with relevant instruments, and enriching their music knowledge. Figure 12(c) shows that few students do not know about the knowledge of music score, and only 1-3 students in each class do not know music score. The main difficulties encountered in the class- room are the difficulty in feeling the emotions expressed by music and the unfamiliarity with professional terms in music.

\section{Research Result Analysis of the Teaching Case}

A questionnaire survey is designed from four aspects, namely, technology application, learning experience, learning process, and the teaching effect to explore students' satisfaction in the intelligent classroom. The results are as follows:

(1) Survey results of the application of the intelligent music classroom

There are four questions related to the content in the questionnaire. The questionnaire divides students' liking degrees for the intelligent classroom into four levels from dislike to love. The results are shown in Figure 13.

Figure 13 shows that $89.6 \%$ of the students have a positive attitude to the intelligent classroom, and only 8 students do not like this teaching mode, indicating that students recognize the new teaching mode. Music teaching in the intelligent classroom has good prospects.

Concerning the use of smart classroom platforms by teachers and students, the results are shown in Figure 14.

The figure shows that the majority of students argue that teachers can quickly find teaching resources related to the course in the system, indicating that teachers are relatively familiar with the use of intelligent classrooms and can skillfully combine the intelligent classroom systems with the 


\begin{tabular}{|c|c|}
\hline Question 10 & Push the preview materials, you can complete it on your own \\
\hline Question 11 & Pre-learning before class can better grasp the knowledge \\
\hline Question 12 & Music, poems and pictures help enhance creative thinking \\
\hline Question 13 & Adapting the singing form to enrich music knowledge \\
\hline Question 14 & Data statistical evaluation is more accurate \\
\hline Question 15 & Timely supplement of teaching content \\
\hline Question 16 & Diversified forms of questioning, stimulate enthusiasm \\
\hline
\end{tabular}

(a)

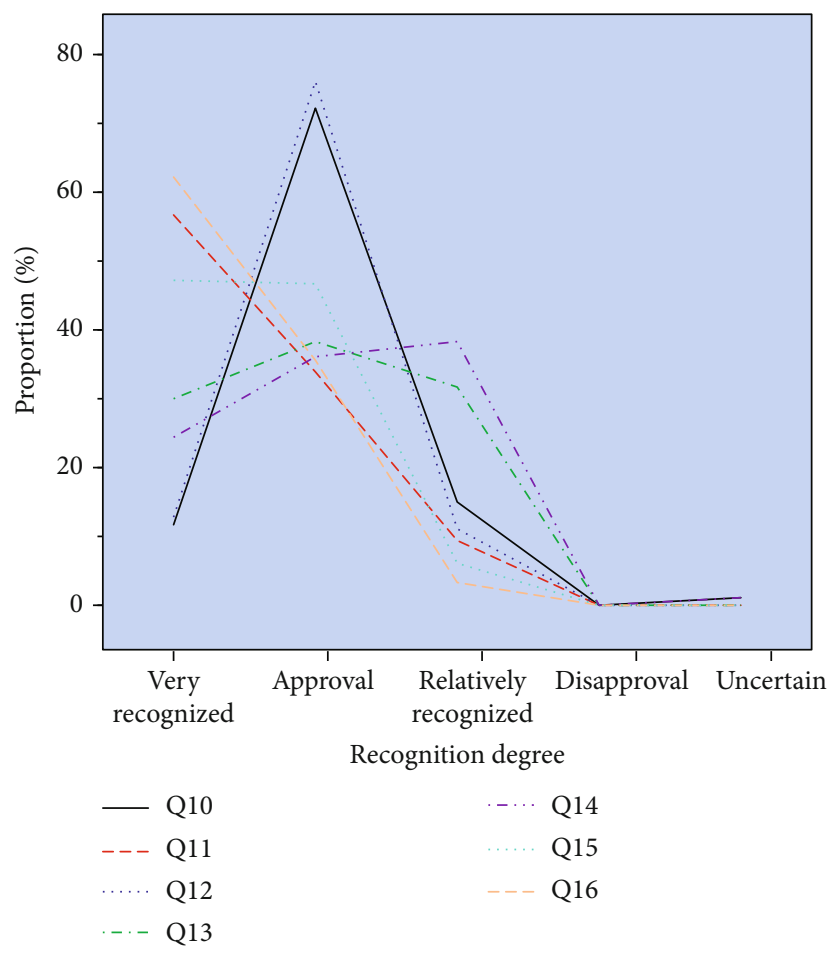

(b)

FIGURE 19: Survey of learning content and process: (a) specific content of the problem; (b) survey results.

teaching content. $89 \%$ of the students think that they do not know about the operation mode of the smart classroom platform. Therefore, teachers need to pay attention to the students' use of tablets in daily teaching, so that students can quickly adapt to this new teaching mode and improve their teaching efficiency.

The last question is about the investigation of the network condition when students use the intelligent classroom system. The results are shown in Figure 15.

Figure 15 shows that only a very small number of students utter that there is no delay in the intelligent classroom teaching, and $79.5 \%$ of the students argue that there are one or two delays in the teaching process. This is because all stu- dents use the network at the same line, which causes signal interference and results in difficulties in getting online smoothly. Therefore, schools should strengthen the stability of network signals to ensure teaching quality.

(2) Survey results of students' learning experience

There are five questions about students' learning experience in the questionnaire, and the results are as follows:

Questions 5 and 6 are about the evaluation of students' experience in the intelligent classroom. Students' experience is divided from dislike to love into four levels, and the final results are shown in Figure 16. 


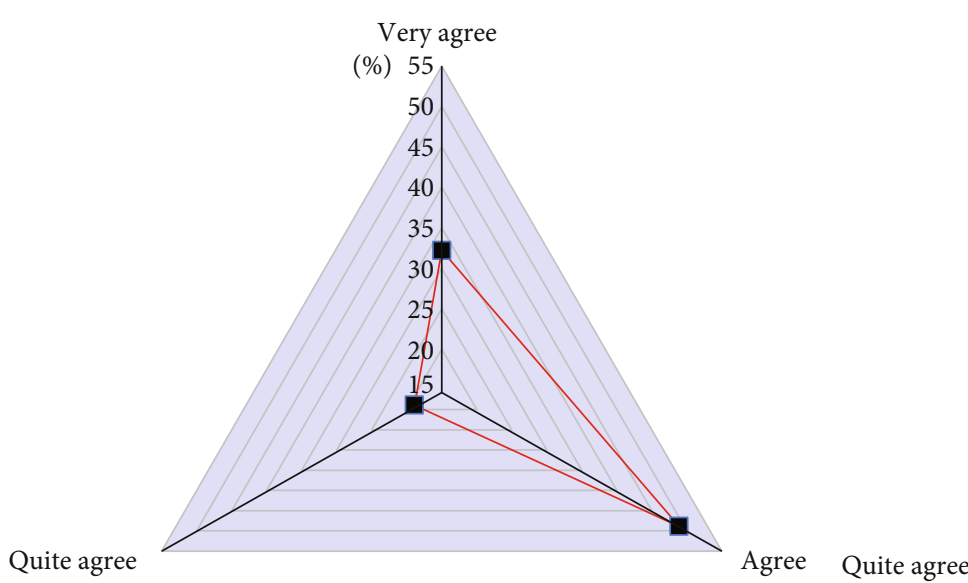

(a)

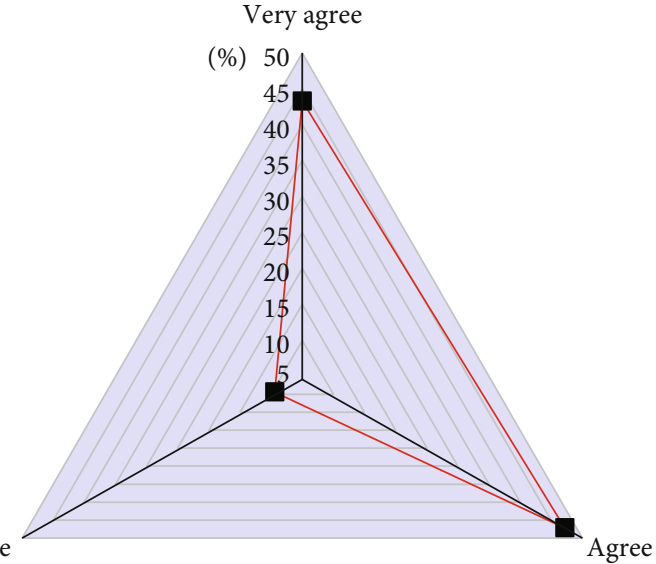

(b)

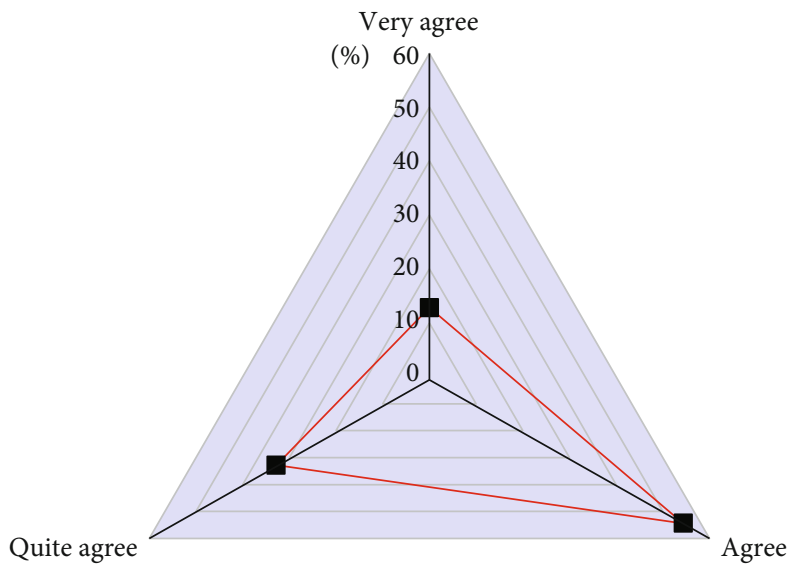

(c)

FIgURE 20: Teaching forms before and during the intelligent class: (a) question 17; (b) question 18; (c) question 19.

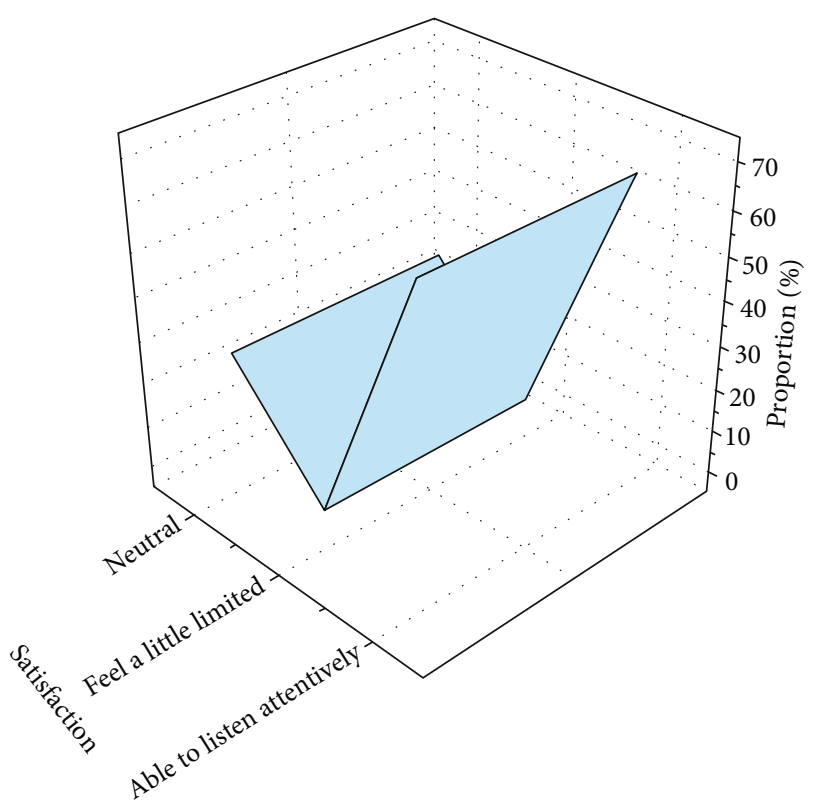

Figure 21: Students' satisfaction with the function of the lock screen of tablets.
Figure 16 shows that $96.6 \%$ of the students hold a positive attitude towards the use of intelligent systems to complete their homework. Only $0.6 \%$ of the students show that they do not like to finish their homework through intelligent systems. $97.2 \%$ of the students like the learning function provided by the intelligent system, and very few students hold a negative attitude towards the learning function provided by the intelligent system. Different from English and other subjects, homework in music class does not attract the attention of teachers and students because teachers cannot give timely feedback to students' problems in learning. The emergence of the intelligent classroom provides teachers with more teaching resources, and student's interest in music class is also aroused.

Questions 7 and 8 are used for the survey of student's satisfaction with the function and questioning form of the free speech platform. The results are shown in Figure 17.

The figure shows that the majority of the students believe that the function of the free speech teaching platform helps to follow up the songs they have learned and agree with the diversified questioning methods of the platform. The use of diversified teaching methods in the classroom can enhance students' interest in learning and can play a regulatory role in the music classroom atmosphere. Question 9 is 


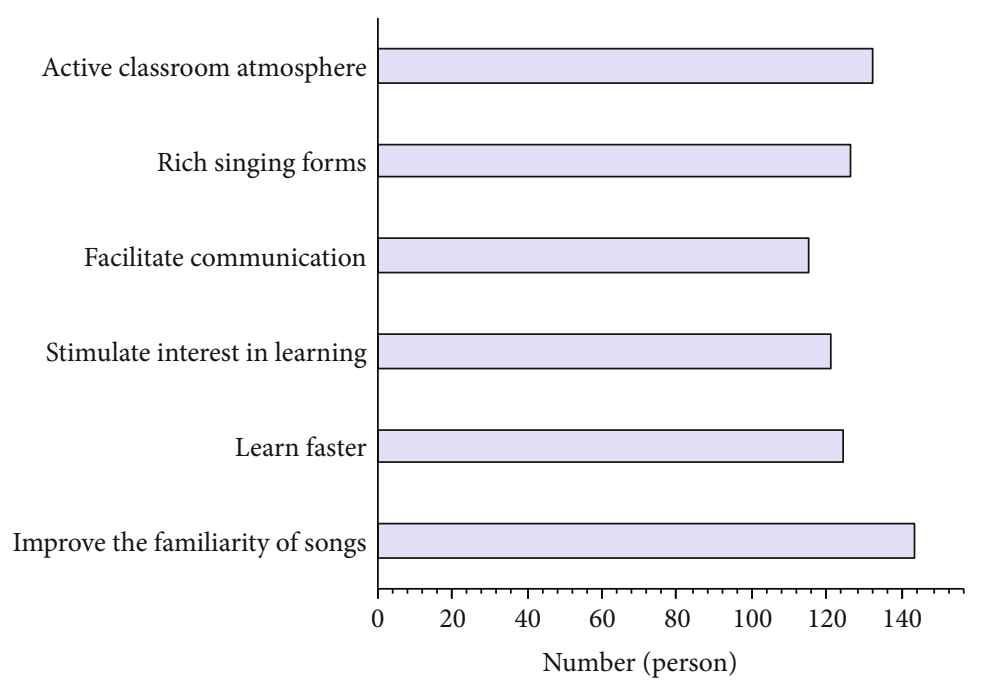

(a)

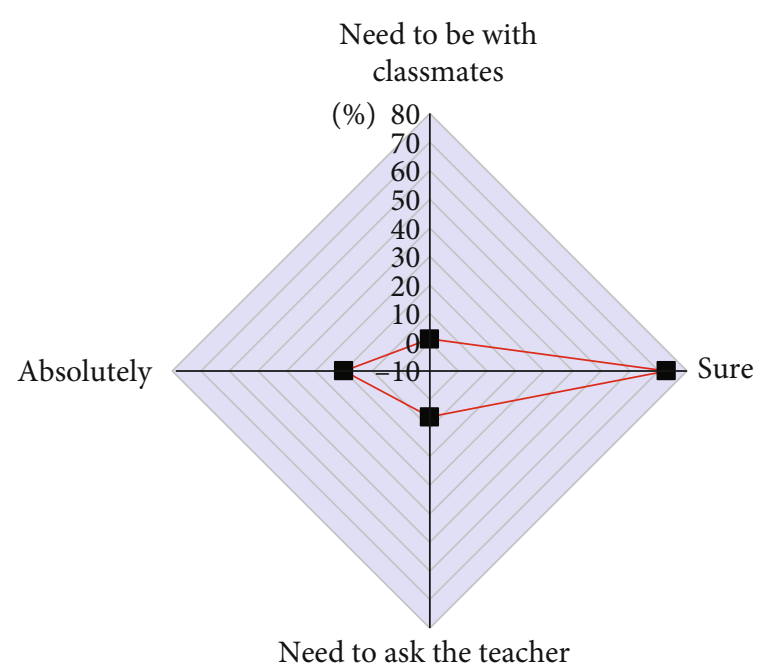

(b)

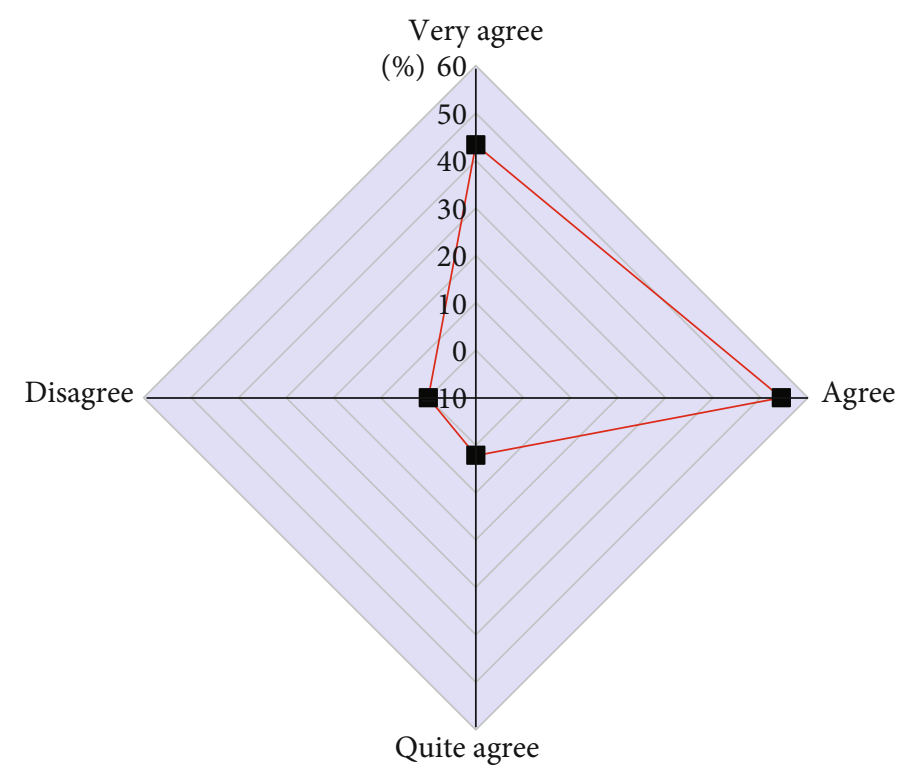

(c)

Figure 22: Survey results of questions 21-23: (a) question 21; (b) question 22; (c) question 23.

used to investigate students' feelings about using tablets for learning. It is a multichoice question, and the results are shown in Figure 18.

Figure 18 shows that a large number of students hold a positive attitude towards using tablets for learning and believe that using tablets for learning can make the classroom atmosphere more active, increase the interaction between teachers and students, and improve students' interest in taking music classes.

(3) Survey results of learning content and process

Questions 9-16 are used for the survey of the learning process. Students' evaluation of the teaching process is shown in Figure 19.

The figure shows that no students hold a negative attitude towards the learning process of the intelligent class- room, and only a very small number of students are uncertain about the related questions. The proportion of students who are highly recognized and approved of this positive attitude is the highest, indicating that this new teaching model can improve students' interest in learning music classes and also make students dare to answer questions in the classroom.

\section{(4) Survey results of the teaching effect}

Questions 17-19 are designed for the investigation of teaching forms before and during class. The results of the investigation are shown in Figure 20.

The specific questions 17-19 in Figure 20 are as follows: combining teaching aids with the classroom teaching technology in music teaching can improve the teaching efficiency; students' satisfaction with the questioning form in 
the teaching process; and students' skill in segmentation rhythm through preclass questions. The figure shows that students recognize the teaching links before and during the intelligent classroom. Question 20 is the survey of the student's satisfaction with the function of the lock screen of tablets. The results are shown in Figure 21.

Figure 21 shows that $67.2 \%$ of the students think that the way that the page of tablets is controlled by the teacher is satisfactory, making them listen carefully attentively. Only $4.4 \%$ of the students hold a negative attitude towards this teaching mode and believe that this way has certain limitations. The survey results of questions 21-23 are shown in Figure 22.

Questions 21-23 are the investigation of the effect of the music intelligent classroom, the completion of homework, and the satisfaction of interactive communication in an intelligent music classroom. Question 21 is a multichoice question due to the difference in students' acceptance of knowledge and the learning speed of each student. The question in Figure $22(\mathrm{a})$ is that the application of the intelligent classroom is conducive to enhancing students' learning ability. The question in Figure 22(c) is that most students hold a positive attitude towards innovative teaching equipment.

\section{Conclusions}

In recent years, the development of wireless networks contributes to setting up a platform for intelligent teaching. The use of tablets, computers, and electronic schoolbags widens students' learning channels and improved students' interest in learning. The intelligent classroom is different from the traditional teaching mode which combines teaching and learning. It integrates some new technologies with classroom teaching, and its goal is to provide students with a better learning environment and improve students' learning effect. Middle school $\mathrm{C}$ is taken as the research object, the current situation of music teaching in middle school $\mathrm{C}$ is analyzed, and the teaching mode of the intelligent music classroom suitable for the actual teaching situation of middle school $\mathrm{C}$ is designed according to the feedback results. And the teaching mode of the intelligent music classroom suitable for middle school $\mathrm{C}$ is applied to the actual teaching process, and the students' feelings for the intelligent music classroom are analyzed, and the teaching effect through the questionnaire survey is explored. The practice shows that the new teaching mode combined with random answers, random classroom tests, and group evaluations can effectively improve students' interest in learning, make teachers fully understand students' learning situation, and timely feedback according to students' learning situation, improving students' learning effect.

\section{Data Availability}

The dataset used to support the findings of this study is available from the corresponding author upon request.

\section{Conflicts of Interest}

The authors declare no conflicts of interest.

\section{Acknowledgments}

This work was supported by the Project of Philosophy and Social Science Research in Colleges and Universities in Jiangsu Province "Research on the Poetic Practice of Improving College Students' Music Aesthetic Literacy" (2019SJA0755) and Project of the Basic Scientific Research Program of Jiangnan University "Research on Jiangnan Poems and Songs from the Perspective of Grand Canal Culture Zone" (JUSRP12087).

\section{References}

[1] R. Li, Z. Zhao, X. Zhou et al., "Intelligent 5G: when cellular networks meet artificial intelligence," IEEE Wireless Communications, vol. 24, no. 5, pp. 175-183, 2017.

[2] T. G. Dietterich, "Steps toward robust artificial intelligence," AI Magazine, vol. 38, no. 3, pp. 3-24, 2017.

[3] F. Jiang, Y. Jiang, H. Zhi et al., "Artificial intelligence in healthcare: past, present and future," Stroke \& Vascular Neurology, vol. 2, no. 4, pp. 230-243, 2017.

[4] P. Glauner, J. A. Meira, P. Valtchev, R. State, and F. Bettinger, "The challenge of non-technical loss detection using artificial intelligence: a survey," International Journal of Computational Intelligence Systems, vol. 10, no. 1, pp. 760-775, 2017.

[5] J. H. Thrall, X. Li, Q. Li et al., "Artificial intelligence and machine learning in radiology: opportunities, challenges, pitfalls, and criteria for success," Journal of the American College of Radiology, vol. 15, no. 3, pp. 504-508, 2018.

[6] T. Yang, A. A. Asanjan, E. Welles, X. Gao, S. Sorooshian, and $\mathrm{X}$. Liu, "Developing reservoir monthly inflow forecasts using artificial intelligence and climate phenomenon information," Water Resources Research, vol. 53, no. 4, pp. 2786-2812, 2017.

[7] C. Cath, S. Wachter, and B. Mittelstadt, "Artificial intelligence and the 'good society': the US, EU, and UK approach," Science and Engineering Ethics, vol. 24, no. 7625, pp. 1-24, 2017.

[8] D. Lloyd, "Annotating pop culture: describe a successful classroom teaching tactic that could be replicated by other instructors," Teaching Theology and Religion, vol. 21, no. 2, pp. 141141,2018

[9] J. Hiebert, E. Miller, and D. Berk, "Relationships between mathematics teacher preparation and graduates' analyses of classroom teaching," Elementary School Journal, vol. 117, no. 4, pp. 687-707, 2017.

[10] V. Balasubramanian and S. Margret Anouncia, "Learning style detection based on cognitive skills to support adaptive learning environment - a reinforcement approach," Ain Shams Engineering Journal, vol. 9, no. 4, pp. 895-907, 2018.

[11] S. Basu, G. Biswas, and J. S. Kinnebrew, "Learner modeling for adaptive scaffolding in a computational thinking-based science learning environment," User Modeling and User-Adapted Interaction, vol. 27, no. 1, pp. 5-53, 2017.

[12] N. A. Yaghmour, T. P. Brigham, T. Richter et al., "Causes of death of residents in ACGME-accredited programs 2000 through 2014: implications for the learning environment," Academic medicine: journal of the Association of American Medical Colleges, vol. 92, no. 7, pp. 976-983, 2017. 
[13] Y. van Rijk, M. Volman, D. de Haan, and B. van Oers, "Maximising meaning: creating a learning environment for reading comprehension of informative texts from a Vygotskian perspective," Learning Environments Research, vol. 20, no. 1, pp. 77-98, 2017.

[14] C. A. Murdoch-Kinch, R. E. Duff, V. Ramaswamy, T. V. Ester, S. A. Sponseller, and J. A. Seeley, "Climate study of the learning environment for faculty, staff, and students at a U.S. dental school: foundation for culture change," Journal of Dental Education, vol. 81, no. 10, pp. 1153-1163, 2017.

[15] Y. Shimada, T. Tanimoto, M. Nishimori et al., "Incidental cerebral aneurysms detected by a computer-assisted detection system based on artificial intelligence: a case series," Medicine, vol. 99, no. 43, article 21518, 2020.

[16] J. Ong, A. Selvam, and J. Chhablani, “Artificial intelligence in ophthalmology: optimization of machine learning for ophthalmic care and research," Clinical and Experimental Ophthalmology, vol. 49, no. 5, pp. 413-415, 2021.

[17] S. Nagao, Y. Tsuji, Y. Sakaguchi et al., "Highly accurate artificial intelligence systems to predict the invasion depth of gastric cancer: efficacy of conventional white-light imaging, nonmagnifying narrow-band imaging, and indigo-carmine dye contrast imaging," Gastrointestinal Endoscopy, vol. 92, no. 4, pp. 866-873.e1, 2020.

[18] L. Haishan, "Application of multiple evaluation in art classroom teaching in rural primary schools," Asian Agricultural Research, vol. 12, no. 8, pp. 76-78, 2020.

[19] A. Colantonio, S. Galano, S. Leccia, E. Puddu, and I. Testa, "A teaching module about stellar structure and evolution," Physics Education, vol. 52, no. 1, article 015012, 2017.

[20] J. Müssig, A. Clark, S. Hoermann, G. Loporcaro, C. Loporcaro, and T. Huber, "Imparting materials science knowledge in the field of the crystal structure of metals in times of online teaching: a novel online laboratory teaching concept with an augmented reality application," Journal of Chemical Education, vol. 97, no. 9, pp. 2643-2650, 2020.

[21] W. Khan and K. Kuru, "An intelligent system for spoken term detection that uses belief combination," IEEE Intelligent Systems, vol. 32, no. 1, pp. 70-79, 2017.

[22] A. al Shorman, H. Faris, and I. Aljarah, "Unsupervised intelligent system based on one class support vector machine and grey wolf optimization for IoT botnet detection," Computing, vol. 11, no. 7, pp. 2809-2825, 2020.

[23] B. Schmucker, F. Trautwein, T. Semm, A. Lechler, M. F. Zaeh, and A. Verl, "Implementation of an intelligent system architecture for process monitoring of machine tools," Procedia CIRP, vol. 96, no. 2, pp. 342-346, 2021.

[24] J. Lee, C. Lim, and H. Kim, "Development of an instructional design model for flipped learning in higher education," Educational Technology Research \& Development, vol. 65, no. 2, pp. 427-453, 2017.

[25] M. Davies, D. Pon, and L. S. Garavalia, "Improving pharmacy calculations using an instructional design model," American Journal of Pharmaceutical Education, vol. 82, no. 2, p. 6200, 2018.

[26] E. Baten, M. Praet, and A. Desoete, "The relevance and efficacy of metacognition for instructional design in the domain of mathematics," ZDM, vol. 49, no. 4, pp. 613-623, 2017.

[27] I. Gksu, K. V. Zcan, and R. Cakir, "Content analysis of research trends in instructional design models: 1999-2014," Journal of Learning Design, vol. 10, no. 2, p. 85, 2017.
[28] A. Bennison, M. Goos, and V. Geiger, "Utilising a researchinformed instructional design approach to develop an online resource to support teacher professional learning on embedding numeracy across the curriculum," $Z D M$, vol. 52, no. 5, pp. 1017-1031, 2020.

[29] M. Klepsch and T. Seufert, "Understanding instructional design effects by differentiated measurement of intrinsic, extraneous, and germane cognitive load," Instructional Science, vol. 48, no. 1, pp. 45-77, 2020.

[30] M. Farashahi and M. Tajeddin, "Effectiveness of teaching methods in business education: a comparison study on the learning outcomes of lectures, case studies and simulations," International Journal of Management Education, vol. 16, no. 1, pp. 131-142, 2018. 